\title{
Publicidad e internet: algunas perlas ocultas en la realidad peruana
}

\section{Andrea Nanette Gonzalez León}

Instituto Nacional de Defensa de la Competencia y de la Protección de la Propiedad Intelectual, Lima, Perú

ResUMEN. El presente artículo pretende acercarnos a la realidad de la publicidad peruana ejercida por los denominados celebrities o influencers. En un principio, tal actividad estaría disfrazada como una recomendación u opinión personal; sin embargo, al ser analizada según los criterios de la Ley de Represión de la Competencia Desleal, se puede concluir que tendría un fin concurrencial en el mercado y, por ende, sería pasible de ser sancionada.

PALABRAS CLAVE: publicidad / referente / redes sociales / competencia desleal

\section{Advertising and the Internet: some hidden pearls in the reality of life in Peru}

Авstract. This article aims at approaching the reality of advertising in Peru by the so-called celebrities or influencers. At first, such activity would be disguised as a recommendation or personal opinion; however, when analyzed under the criteria of the Law of Repression of Unfair Competition, it can be concluded that advertising in Peru has a concurrent purpose in the market and, therefore, is liable to be sanctioned. 


\section{INTRODUCCIÓN}

La globalización y la facilidad para acceder a internet han presupuesto, en el contexto mediático, múltiples cambios relevantes en la vida de las personas, así como en la forma de incentivar mayores transacciones a favor de los proveedores. En la actualidad, con solo un clic es posible comunicarse con alguien de cualquier parte del mundo, realizar una compra de China a Perú, entre otras acciones similares, sin tener que conocer o hablar con la "persona" que se encuentra al otro lado de la red. Por ello, tanto las empresas que llevan determinado tiempo en el mercado como los nuevos emprendedores no han dejado pasar la oportunidad para ofrecer sus productos o servicios a través de la red, lo que resulta muchas veces económicamente más eficiente.

En medio de estos cambios, la actividad publicitaria no podía perder protagonismo. Ahora ya no solo se hace publicidad mediante radio, televisión y prensa escrita, sino también a través de las redes sociales, los buscadores y otro tipo de páginas que se lanzan día a día en la red. Lo único que ha cambiado es el soporte, lo que se llama era digital. Por ello, en estos últimos años, la mayoría de los anunciantes han ido trabajando diversas estrategias para posicionar su marca en el mercado no solo nacional, sino también mundial, adaptándose a las diversas necesidades y gustos de los consumidores, quienes suelen pasar muchas horas del día conectados a las redes sociales.

Ante esta nueva era, la publicidad como tal cumple un papel importante, en tanto que rompe barreras que antes no podía traspasar, como el tamaño y alcance de una determinada marca, entre otros factores.

Como medio publicitario, el valor más destacable de internet es que ha permitido el acceso a todo tipo de anunciantes sin importar el tamaño o naturaleza del mismo; es decir, una pequeña o mediana empresa, cuyo ámbito de actuación esté muy localizado geográficamente, puede competir con una gran empresa nacional o, incluso, con una multinacional en igualdad de condiciones, planificando sus campañas online con las mismas herramientas y consiguiendo resultados muy similares en cuanto a efectividad. Es lo que se llama la democratización de la publicidad. (Muela, 2008, p. 185)

En este artículo, se pretende dar un nuevo enfoque a la calidad de anunciante con que cuentan los celebrities o influencers, quienes brindan "recomendaciones" $\mathrm{u}$ "opiniones" sobre diversos productos o marcas a 
través de sus blogs, páginas o redes sociales -en especial, Facebook, Twitter e Instagram-, que resultan ser más que sospechosas. Al respecto, resulta importante mencionar que la publicidad interactiva revierte mayor rentabilidad económica y comunicativa en comparación con otros medios tradicionales.

\section{Breve análisis del Decreto Legislativo 1044}

En el Perú, la regulación sobre competencia desleal se encuentra actualmente establecida en el Decreto Legislativo 1044, Ley de Represión de la Competencia Desleal ${ }^{1}$. Sobre el particular, cabe precisar que dicha norma derogó el Decreto Ley 26122 (antigua Ley sobre Represión de la Competencia Desleal) y el Decreto Legislativo 691, Normas de la Publicidad en Defensa del Consumidor, las cuales, como su mismo nombre lo indica, trataban los temas de publicidad y defensa del consumidor, por lo que resultó necesario realizar la integración de ambos decretos.

En este punto, conviene señalar que en la Ley de Represión de la Competencia Desleal no solo se ha unificado la normativa referida a publicidad y defensa del consumidor, sino que también se ha plasmado la tendencia jurisprudencial desplegada por el Instituto Nacional de la Competencia y de la Protección de la Propiedad Intelectual (Indecopi) por más de diez años. Por lo tanto, esta norma podría ser considerada como una manifestación expresa del desarrollo de la casuística peruana.

Sobre el particular, en la parte considerativa de la Ley de Represión de la Competencia Desleal, se procuró dar un alcance, entre otros, sobre los refuerzos que se realizaron de acuerdo con las necesidades observadas en la casuística y con las que surgieron en el mercado. Así, se destacó el principio de la primacía de la realidad, además de establecerse conceptos claros y criterios de análisis que puedan generar mayor predictibilidad en la aplicación de la norma a fin de establecer y esclarecer las conductas que podrán ser consideradas como desleales.

$\mathrm{Al}$ respecto, el artículo 5 de la Ley de Represión de la Competencia Desleal señala:

1 Publicada el 26 de junio del 2008 y vigente desde el 27 de julio del mismo año. 
Artículo 5.- Primacía de la realidad

La autoridad administrativa determinará la verdadera naturaleza de las conductas investigadas, atendiendo a las situaciones y relaciones económicas que se pretendan, desarrollen o establezcan en la realidad. La forma de los actos jurídicos utilizados por los contratantes no enerva el análisis que la autoridad efectúe sobre la verdadera naturaleza de las conductas subyacentes a dichos actos. (Decreto Legislativo 1044, 2008)

El principio de la primacía de la realidad permite a la Administración determinar la verdadera naturaleza de las conductas, a fin de verificar si un competidor incurre en un acto de competencia desleal. Para esto, se podrán observar las situaciones y relaciones económicas que se pretendan, desarrollen o establezcan en la realidad. En virtud de ello, se podría decir que este principio es una puerta de acceso para que se puedan determinar nuevas conductas que no se encuentren tipificadas en el listado de la Ley de Represión de la Competencia Desleal, pero que podrían ser consideradas como actos desleales, en atención a las nuevas tendencias e innovaciones que surgen en el mercado.

\section{Concepto de competencia desleal}

Como es bien sabido, el mundo se encuentra ante una economía social de mercado, que se puede entender como un modelo mixto: económico y social. Con él se pretende, a través de la libre iniciativa y la competencia, el avance y mejora económica, permitiendo incluso la intervención del Estado en ciertas materias.

Así las cosas, y procurando el bienestar social del mercado, diversos agentes económicos (empresa, consumidor, Estado) pugnan para lograr la mayor realización de transacciones sobre bienes y servicios ofrecidos, lo que genera una real competencia constante e intensa. Sobre el particular, se puede señalar que la transacción comercial lograda por una determinada empresa será una menos que pueda conseguir su competidor. No obstante, si bien esa transacción perjudicó a la segunda empresa mencionada, lo cierto es que dicha conducta en sí misma no puede ser considerada como desleal, siempre que se haya dado en atención a las buenas prácticas, ofertas superiores, mayor y mejor información (clara, veraz, oportuna, entre otros), mayor calidad en los productos o servicios, entre otros, es decir, en atención a la eficiencia. Sin embargo, cuando la empresa A logra realizar una transacción mediante prácticas que van en contra de la 
buena fe empresarial, estas serán consideradas como desleales y, por ende, sancionadas por la Administración.

En esa línea, en el ámbito general del derecho de la competencia se distinguen dos espacios de regulación. Por un lado, la represión de conductas anticompetitivas, destinadas a limitar o restringir la libre competencia por parte de los agentes económicos; y, por otro lado, la represión de la competencia desleal, que se explicará más adelante (Baylos, 1993, p. 284).

Entonces, se puede concluir que un acto se considera "desleal" cuando un competidor (empresa A) busca para sí mismo un beneficio económico por medios ajenos a su propia eficiencia, de manera que perjudica a su competencia (empresa B o un determinado sector económico) y vulnera la buena fe empresarial.

\section{Sobre la cláusula general}

A partir de lo anterior, es pertinente ofrecer un pequeño alcance sobre la tan famosa cláusula general, que se encuentra regulada en el artículo 6 de la Ley de Represión de la Competencia Desleal:

Artículo 6.- Primacía de la realidad

6.1.- Están prohibidos y serán sancionados los actos de competencia desleal, cualquiera que sea la forma que adopten y cualquiera que sea el medio que permita su realización, incluida la actividad publicitaria, sin importar el sector de la actividad económica en la que se manifiesten.

6.2.- Un acto de competencia desleal es aquel que resulte objetivamente contrario a las exigencias de la buena fe empresarial que deben orientar la concurrencia en una economía social de mercado. (Decreto Legislativo 1044, 2008)

En la definición de un acto de competencia desleal, resulta complicado determinar de manera objetiva el significado de la "buena fe empresarial"; no obstante, discrepamos de algunos autores que mantienen que esta podría ser considerada como un concepto incompleto. Contrariamente, se podría sostener que el artículo 6 de la Ley de Represión de la Competencia Desleal fue redactado intencionalmente de esa manera, esto es, con un motivo totalmente válido. Este sería abarcar en una definición amplia todas aquellas conductas que no se encuentren enumeradas, en forma expresa, en el contenido de la referida norma, en 
tanto que ello no resulta posible, pues implicaría ejemplificar todos los supuestos de deslealtad en las prácticas comerciales.

Al respecto, Baylos (1978) señala:

Un acto es desleal, a los efectos de la ley, solamente con que incurra en la noción contenida en la cláusula general, sin que sea preciso que, además, figure tipificado en alguno de los supuestos que se enumeran, que poseen solo un valor ilustrativo y ejemplificador. (p. 317)

Por lo expuesto, se puede concluir preliminarmente que, en el caso concreto del modelo de economía social de mercado, se podría entender como buena fe empresarial aquello que caracteriza a la competencia dentro de los márgenes de la eficiencia de las prestaciones que se ofrecen en el mercado. Esto termina beneficiando a los consumidores (al ofrecer mejor calidad en productos y servicios, precios competitivos, entre otros) y también a los proveedores, pues promueve que estos procuren brindar mejores bienes y servicios en el mercado a través de diversas mejoras, como lo es la innovación. Así, los actos contrarios al concepto anterior podrían ser comprendidos como actos que van en contra de la buena fe comercial y, por ende, están inmersos en lo regulado por el artículo 6 de la Ley de Represión de la Competencia Desleal.

\section{Publicidad a través de las redes sociales}

A menudo, diversas personas son consideradas como "referentes" en temas tales como moda, deportes, tecnología, etcétera. Las podemos leer a diario a través de distintas redes sociales, en las que dan consejos de alimentación, vestimenta, accesorios y más. Estos "referentes", por lo general, nos hablan de sus preferencias, características, nuevas atracciones sobre un producto o servicio determinado, entre otros, colocando el nombre de la marca e incluso la dirección del proveedor. Respecto de esto, surge la siguiente interrogante: ¿la recomendación u opinión de este "referente" puede ser calificada como publicidad?

Ante esta ola de comentarios, recomendaciones u opiniones sobre un producto o servicio emitido por una persona considerada como "referente" en el mundo entero, se genera una serie de problemas que es pertinente describir con algunos ejemplos. Así, en el año 2012, Wayne Rooney, en ese entonces jugador del Manchester United, publicó en su cuenta personal del Twitter lo siguiente: 


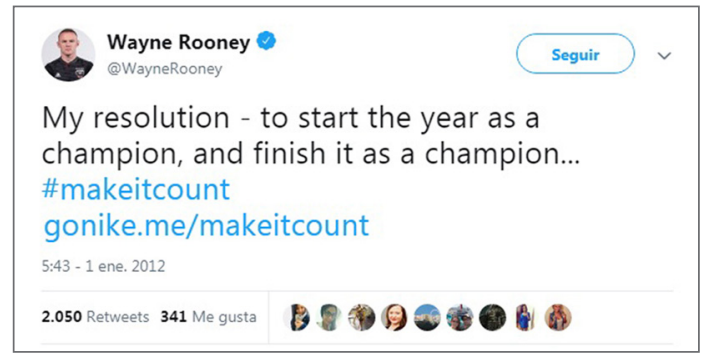

Fuente: Rooney (2012)

Este caso provocó una controversia porque Nike había lanzado una campaña publicitaria en el Reino Unido bajo la denominación MakeItCount, para lo cual pactó con el futbolista antes mencionado y con otros más la publicación de un mensaje en Twitter utilizando el hashtag \#makeitcount, además de un enlace que remitía a la página web de esta empresa. Cabe señalar que estos jugadores son considerados como "referentes" de temas relacionados con deportes; empero, estos tuits no denotaban tener un carácter comercial o publicitario.

Al respecto, el 20 de junio del 2012, la Advertising Standards Authority (ASA) ${ }^{2}$, el organismo británico de control publicitario, emitió una resolución en la que declaró fundado el reclamo presentado en contra de los diversos tuits publicados por Wayne Rooney y otros jugadores del medio internacional, al juzgarlos como publicidad encubierta. Asimismo, ordenó a la empresa Nike el retiro de la publicidad objeto del reclamo y la identificación de sus campañas publicitarias como tales.

$\mathrm{Al}$ igual que en el caso de Nike, diversas celebrities han cobrado una fortuna por emitir un "comentario espontáneo" a través de sus cuentas en redes sociales. Por ejemplo:

Para el año 2012, Kim Kardashian cobraba 10000 dólares (unos 7600 euros) por cada tuit recomendando un producto; el rapero Snoop Dogg, alrededor de 8000 dólares (6100 euros) por un tipo de publicidad disfrazada de mensaje espontáneo y personal; hasta los 50000 dólares que llegaron a pagar a Charlie Sheen por los tuits patrocinados para Internship.com. La compañía logró más de 95333 clics en la primera hora y 74040 solicitudes de empleo. (Cuesta, 2016, párr. 3)

2 La Advertising Standards Authority (ASA) es el regulador de la publicidad independiente del Reino Unido. 
Por otro lado, la ASA comenzó a rastrear las redes en el 2012 tras una sospechosa "campaña encubierta" de la marca de chocolates Snickers, en la que repentinamente celebrities como el boxeador Amir Khan, la cantante de Factor X, Cher Lloyd, el comentador de críquet Ian Botham, el entonces jugador del Manchester United, Rio Ferdinand, y la actriz Katie Price, tuitearon exactamente la misma frase debajo de una foto con la chocolatina: "No eres tú mismo cuando estás hambriento". Finalmente, consideró estimar el reclamo.

En atención a ello, el hecho de que una persona reconocida pueda generar mucho valor a una empresa por emitir un comentario respecto de una determinada marca de producto o servicio resulta ser una forma de difundir publicidad. Correspondería preguntarnos: ¿hasta qué punto es lícita esta práctica tan "normal" en diversos medios y mercados?

En algunos países, como España y Estados Unidos, por citar algunos ejemplos, estas prácticas se encuentran reguladas, sea por la jurisprudencia o por las propias normas nacionales. Así, España exige a los anunciantes que, cuando emitan alguna publicidad que parte de un comentario, recomendación u opinión, debe quedar claro para los consumidores que esta tiene naturaleza publicitaria, por ejemplo, a través de un hashtag o un video promocional que indique claramente que la frase expresada por el "referente" es producto de una campaña publicitaria. En Estados Unidos, se demanda la inclusión de indicaciones expresas sobre la verdadera naturaleza publicitaria de un contenido, a través de hashtags del tipo \#ad, \#publi, \#spon o similares. Esta obligación es muy fuerte para los blogueros y ya es una práctica común en esta industria.

\section{Publicidad en internet: el Caso peruano}

En el Perú, no se encuentra regulado el tipo de prácticas publicitarias que se han mencionado en el punto anterior. Sin embargo, en el mercado nacional hay diversos indicios de que en nuestro país también se cuenta con esta publicidad encubierta a través de los denominados "referentes". No obstante, estos no son pasibles de formar parte de un procedimiento sancionador (como imputados) porque, de acuerdo con el criterio adoptado por la autoridad administrativa, si no se acredita que existe una competencia directa, no habría un fin concurrencial y, por tanto, no se encontraría bajo los supuestos para determinar 
responsabilidad administrativa, según los supuestos establecidos en la Ley de Represión de la Competencia Desleal.

$\mathrm{Al}$ respecto, el capítulo II de la Ley de Represión de la Competencia Desleal, referido a los criterios para la determinación de responsabilidad, dispone en su artículo 21 lo siguiente:

Artículo 21.- Interpretación de la publicidad

21.1.- La publicidad es evaluada por la autoridad teniendo en cuenta que es un instrumento para promover en el destinatario de su mensaje, de forma directa o indirecta, la contratación o el consumo de bienes o servicios. (Decreto Legislativo 1044, 2008)

De acuerdo con lo señalado por la norma, es posible indicar que el mensaje puede ser difundido de manera directa o indirecta. Siendo así, se puede decir preliminarmente que el mensaje emitido por una persona en el que se advierta su opinión o recomendación respecto a un determinado bien o servicio, en función de sus atributos, beneficios, características, entre otros, sí podría ser considerado como publicidad. Ahora bien, en el caso peruano, también se debe tomar en cuenta la calidad de anunciante del administrado, que será producto de una investigación o denuncia, según sea el caso. Sobre el particular, Indecopi ha establecido un criterio que ha sido validado durante varios años:

$\mathrm{Al}$ respecto, cabe mencionar que la concurrencia en el mercado, concepto establecido en el artículo 2 de la Ley de Represión de la Competencia Desleal, es un requisito indispensable para la aplicación de dicho cuerpo normativo. Por ello, si una determinada persona natural no concurre en el mercado, no le serán aplicables las disposiciones establecidas en la Ley de Represión de la Competencia Desleal. [...]

De acuerdo con el referido enunciado normativo, solo aquellos agentes que directamente realizan actividad económica en el mercado, sea como ofertantes o demandantes de bienes o servicios, pueden ser pasibles de responsabilidad administrativa en el marco de la Ley de Represión de la Competencia Desleal. (Resolución 032-2017/CCD, 2017)

Bajo este criterio, un bloguero o un jugador de fútbol reconocido en el mercado peruano podría opinar o recomendar una determinada marca, o "promocionar" una campaña publicitaria; sin embargo, en tanto se pueda advertir que no realiza una actividad económica en el mercado de manera directa, no podrá encontrarse bajo las normas de la Ley de Represión de la Competencia Desleal. 
Sobre el particular, el inciso c) del artículo 59 de la Ley de Represión de la Competencia Desleal señala expresamente que un anunciante será toda persona natural o jurídica que desarrolla actos cuyos efectos o finalidad directa o indirecta sea concurrir en el mercado y que, por medio de la difusión de publicidad, se propone: (i) ilustrar al público, entre otros, acerca de la naturaleza, características, propiedades o atributos de los bienes o servicios cuya producción, intermediación o prestación constituye el objeto de su actividad; o (ii) motivar transacción para satisfacer sus intereses empresariales.

Cabe destacar que tanto el diseño como el tono con el que aparece el mensaje objeto de publicación podrían dar a entender que es eminentemente personal, espontáneo y voluntario del titular de la cuenta, cuando ello no sería así. Entonces, se concluiría que, contrariamente al criterio establecido por Indecopi, en el caso de que alguien considerado como "referente" hiciera una publicación en sus redes sociales o en un blog - bajo los parámetros antes expuestos-, este sí debería ser considerado como un anunciante. Si bien no se puede generalizar, lo cierto es que existen estudios donde se ha podido comprobar que muchos de ellos (blogueros y demás personas reconocidas en determinadas industrias) mantienen un contrato con las agencias de publicidad o con la misma marca.

En este punto, resulta pertinente recordar el ya citado artículo 5 de la Ley de Represión de la Competencia Desleal, donde se indica claramente que la autoridad administrativa podrá determinar la verdadera naturaleza de las conductas. En ese sentido, para los casos de afirmaciones emitidas por celebrities o influencers, se advierte que, si bien estos agentes pueden no ser competidores directos de un determinado proveedor, lo cierto es que, al recibir una contraprestación económica por decir una "recomendación" u "opinión" resaltando las cualidades o ventajas de un determinado bien o servicio través de diversos medios de comunicación, sí se podría afirmar que existe un fin concurrencial en el mercado.

Por otro lado, el mismo artículo 5 de la Ley de Represión de la Competencia Desleal señala que, para determinar la verdadera naturaleza de las conductas, se podrán observar las situaciones y relaciones económicas que se pretendan, desarrollen o establezcan en la realidad. Así pues, no es difícil notar que un "referente" - como un jugador reconocido de fútbol, un bloguero, un chef famoso, entre otros - puede que no compita directamente en el mercado, pero a través de su opinión 
podría generar en sus seguidores una preferencia por una determinada marca, producto o servicio.

Ahora bien, es evidente que, durante la investigación preliminar o en la tramitación de un procedimiento sancionador, los proveedores muy difícilmente ponen a disposición los contratos de prestación de servicios suscritos con las personas a las que hemos denominado "referentes" o los pagos realizados a su favor. Sin la presencia de estos documentos, se podría evitar que se sancione al "referente" y continuar difundiendo diversas publicidades disfrazadas de opiniones o recomendaciones personales. Sin perjuicio de lo señalado en el punto anterior, se considera que Indecopi debe y puede buscar mayores elementos que le permitan concluir si el "referente" realmente califica como anunciante, pese a no contar con los documentos que lo certifiquen - considerando cómo funciona el mercado en la realidad-, junto con otros indicios o medios probatorios.

Por ejemplo, la bloguera Sue Anne Dunlevie tiene un blog denominado Successful Blogging ${ }^{3}$, donde habla, aconseja y brinda asesoría para tener un "blog exitoso". En su historia, ella misma refiere cómo el hecho de contar con un blog puede brindar grandes ingresos económicos a través de la publicidad. Por lo visto, en este y otros muchos casos, administrar un blog tiene un fin lucrativo y la mayoría de las veces estos ingresos provienen de la publicidad. Así, podría quedar acreditado, una vez más, que estas personas sí son anunciantes.

Por ello, y en atención al principio de primacía de la realidad, se puede afirmar que si uno de estos "referentes" percibe una contraprestación económica - o se cuenta con los suficientes indicios de ello- a fin de emitir su "opinión" o "recomendación", esta persona sí podría ser considerada como anunciante y, por ende, pasible de ser sancionada en caso de que cometa actos de competencia desleal. Asimismo, estos "referentes" deberían consignar en sus publicaciones palabras o características tales que permitan al receptor del mensaje determinar claramente que se encuentra ante una publicidad y no ante una "opinión" o "recomendación" que surgió de manera espontánea. Por ejemplo, como ya se hace en otros países, colocar \#sponsor, \#publi, entre otros.

3 El blog se encuentra en el siguiente enlace: http://www.successfulblogging.com/about/ 
Por otro lado, cabe señalar que sí es posible estar ante actos de competencia desleal, en la medida en que se podría generar una desventaja al competidor de manera contraria a la buena fe empresarial. Esto se debería a que tales mensajes logran llegar a miles de personas que, de una u otra forma, toman conocimiento de la afirmación formulada por el "referente" $\mathrm{y}$, de modo inmediato o no, generan una decisión de compra.

Finalmente, lo que se pretende en este artículo es brindar una herramienta de utilidad frente a la realidad actual de las prácticas publicitarias en las redes sociales y otros medios a través de internet, lo que ha brindado gran versatilidad y mayor alcance a los diversos agentes del mercado. Este hecho, en términos generales, no resulta mal, debido a que - como ya se ha señalado - la globalización ha permitido que nuevos y pequeños emprendedores puedan ingresar al mercado, así como que los ofertantes de productos o servicios se esfuercen por brindar mejores y mayores beneficios a fin de lograr más transacciones. Sin embargo, ello no exime la responsabilidad de estos frente a las obligaciones y principios establecidos por la norma publicitaria peruana.

\section{Conclusiones}

Hoy por hoy, la publicidad es aún más interactiva de lo que era hace unos diez años atrás. El anunciante ha buscado - y ha encontrado- la forma de hacer llegar su marca a través de diversas plataformas, y los receptores de estos mensajes publicitarios cada vez pueden acceder más fácilmente a esa información.

Tanto las empresas dueñas de las marcas como las agencias publicitarias han demostrado un espíritu inversor, que ha buscado formas de aproximarse a los agentes del mercado de una manera más rápida y efectiva. Una de las formas que se practican en el mundo es la contratación de diversos celebrities o influencers para que brinden "recomendaciones" u "opiniones", a cambio de una contraprestación económica, sobre diversos productos, marcas o campañas publicitarias a través de sus blogs y páginas en diversas redes sociales, tales como Facebook, Twitter e Instagram.

En el Perú, este tipo de prácticas publicitarias no se encuentra regulado, y no se pretende ello. Sin embargo, se considera pertinente que se modifique o amolde el criterio que viene aplicando la autoridad administrativa para determinar, en primer lugar, la calidad de anunciante de 
los celebrities o influencers; $\mathrm{y}$, en segundo lugar, para sancionarlos ante la comisión de un acto de competencia desleal, de acuerdo con lo establecido en la Ley de Represión de la Competencia Desleal.

Por último, lo que se persigue es que, ante las nuevas tendencias para hacer llegar mensajes comerciales a los usuarios de la red, las cuales son cada vez más novedosas y agresivas - por decirlo de algún modo-, se implanten mecanismos que permitan el éxito y la eficiencia en las buenas prácticas comerciales. De esta manera, se continúa con los grandes pasos que ha dado Indecopi en materia publicitaria, siempre en pos del bienestar y resguardo de la economía peruana.

\section{REFERENCIAS}

Baylos, H. (1978). Tratado de derecho industrial, propiedad industrial, propiedad intelectual, derecho de la competencia económica. Madrid: Civitas.

Baylos, H. (1993). Tratado de derecho industrial, propiedad industrial, propiedad intelectual, derecho de la competencia económica, disciplina de la competencia desleal (2. ${ }^{\mathrm{a}}$ ed.). Madrid: Civitas.

Cuesta, L. (13 de abril del 2016). Publicidad encubierta: la verdad de los tuits patrocinados en tu timeline. Recuperado de http://www. imf-formacion.com/blog/marketing/?s=Publicidad+encubierta $\%$ 3A+la+verdad+de+los+tuits+patrocinados+en+tu+timeline

Decreto Legislativo 032-2017/CCD, Ley de Represión de la Competencia Desleal. (26 de junio del 2008). Recuperado de http://www2.congreso.gob.pe/sicr/comisiones/2011/com2011defconorgregserpub. nsf/pubsfoto/DE4B618D9F9243F305257A3300544E79/\$FILE /01044[1].PDF

Muela, C. (2008). La publicidad en internet: situación actual y tendencias en la comunicación con el consumidor. Zer. Revista de Estudios de Comunicación, 13(24), 183-201. Recuperado de http://www.ehu. eus/ojs/index.php/Zer/article/view/3616

Resolución 0332-2017/CD-INDECOPI. (2017). Tribunal de Defensa de la Competencia y de la Propiedad Intelectual: Sala Especializada en Defensa de la Competencia. Recuperado del sitio de internet del Instituto Nacional de Defensa de la Competencia y de la Protección de la Propiedad Intelectual: https://www.indecopi.gob.pe/inicio 
Rooney, W. [@WayneRooney]. (1 de enero del 2012). My resolution - to start the year as a champion, and finish it as a champion... [tuit]. Recuperado de https://twitter.com/WayneRooney/status/1534713 28018640896?s=19 